\title{
Effect of lubricants and sliding conditions on the tribo-performance of $\mathrm{SiO}_{2} /$ epoxy composites
}

\author{
J. T. Shen ${ }^{1}$, M. Top ${ }^{1}$, F. Van Rijn ${ }^{2}$, Y. T. Pei ${ }^{1,2}$ \\ \& J. Th. M. De Hosson ${ }^{1}$ \\ ${ }^{I}$ Materials innovation institute M2i, Department of Applied Physics, \\ University of Groningen, The Netherlands \\ ${ }^{2}$ Department of Advanced Production Engineering, \\ Engineering and Technology Institute Groningen, \\ University of Groningen, The Netherlands
}

\begin{abstract}
The influence of solid lubricants, normal load, sliding speed and water environment on the tribo-performance of solid lubricant-containing $\mathrm{SiO}_{2}$-epoxy composites is investigated. 10 to $15 \mathrm{wt} \%$ PTFE concentration yields a low coefficient of friction (CoF) and low wear rate under $60 \mathrm{~N}$ load. With increasing PTFE concentration in the composites, the load capacity decreases. Graphite exhibits worse friction and wear performance than PTFE under dry sliding condition, i.e. the $\mathrm{CoF}$ increases with a decreasing load in ball-on-disc. A higher concentration of PTFE-containing tribolayer on the worn composite surface is found under a higher load. The $\mathrm{CoF}$ and ball wear rate increase with increasing sliding speed under dry sliding, which is accompanied with an increase of the surface temperature of the composite. A high relative humidity is advantageous for a low friction due to adsorbed water molecules that lubricate the sliding couple. Water lubrication leads to a lower wear rate of the PTFE and graphite filled composites, whereas it gives rise to a higher wear rate of the $\mathrm{Al}_{2} \mathrm{O}_{3}$ ball due to the lack of protection of the transfer films.

Keywords: PTFE, graphite, friction, load, speed, water.
\end{abstract}




\section{Introduction}

Polytetrafluoroethylene (PTFE) and graphite filled composites are commonly used in dry sliding bearings, due to the self-lubricating and maintenance-free properties. The excellent tribo-performance of a PTFE filled epoxy composite with a high concentration of $\mathrm{SiO}_{2}$ particles has been shown in our previous publication [1]. The tribo-performance of PTFE filled composites is closely related to the formation mechanism, thickness and stability of PTFE transfer films on the counterparts. It is generally accepted that an easy sliding motion between the transferred PTFE and the PTFE on the composite surface could greatly reduce the friction. Graphite has a layered structure, i.e. crystallography consists of planes of polycyclic carbon atoms. The weaker van der Waals bonding between planes due to the separating distance of carbon atoms offers graphite a good lubrication property.

The influence of the loading conditions on the coefficient of friction $(\mathrm{CoF})$ of PTFE-based composites has also been extensively reported. It is found that the CoF decreased with increasing load [2-5], Kragelskii explained such a behavior by elastic deformation of the surface asperities [6]. However, the role of load, or more specifically contact pressure, on the formation of transfer films and tribolayers has not been systematically examined. Since different sliding speeds are used in various applications, the influence of sliding speeds on the triboperformance of composites is also important to examine.

The effect of humidity on the tribo-performance of PTFE and PTFE filled composite is still obscure in literature. Tanaka and Miyata found that the friction of PTFE decreases with increasing humidity in the environment [7], whereas Krick et al. [8] found a trend of increasing friction coefficient of PTFE/alumina composites with increasing relative humidity from $2.7 \%$ to $78 \%$. As to sliding under water lubrication, Krick et al. [8] and Mens and De Gee [9] measured a lower $\mathrm{CoF}$ and a higher wear rate of PTFE-based composites in a water submerged experiment than in dry conditions. In contrast Jia et al. found that the wear rate and the friction coefficient of PTFE-based composites are lower under water lubricated sliding [10]. Adsorption of water vapor onto graphite surface was found to be advantageous for a low CoF [11, 12], but the influence of water-lubrication on the friction of graphite/epoxy composites can hardly been found in literature.

In this work, the influence of different types and different concentrations of solid lubricants on the mechanical property and tribo-performance are investigated. The effect of sliding speed and normal load, as well as relative humidity and water lubrication on the tribo-performance of epoxy composites filled with solid lubricants is studied as well. This work offers a better understanding of the effect of lubricants and sliding conditions on the selflubricating composites. 


\section{Experiments}

\section{1 $\mathrm{SiO}_{2}$ /epoxy composites filled with PTFE or graphite}

The epoxy- and $\mathrm{SiO}_{2}$-containing powder, Epomet $\mathrm{F}$, was purchased from Buehler $\mathrm{GmbH}$. The powder is mainly composed of about $31 \pm 2 \mathrm{wt} . \%$ epoxy resin (CAS: 26265-08-7) and about $65 \pm 2$ wt. $\% \mathrm{SiO}_{2}$ particles $(20-100 \mu \mathrm{m})$. It also contains 1-3 wt.\% 2,4,6-tris(dimethylaminomethyl)phenol, 1-2 wt.\% antimony oxide $\left(\mathrm{Sb}_{2} \mathrm{O}_{3}\right)$ particles (for flame retardant property) and less than 1 wt.\% carbon black (pigment). The little amount of $\mathrm{Sb}_{2} \mathrm{O}_{3}$ and carbon black was found to give negligible lubrication to the sliding system [1]. The PTFE powder, Zonyl MP 1000 fluoro-additive, was purchased from DuPont. The graphite powder (SigmaAldrich), has particle size $<20 \mu \mathrm{m}$. After mechanically mixing the two powders for 30 minutes, the mixed powder was cured at about $160^{\circ} \mathrm{C}$ for 20 minutes under $0.41 \mathrm{MPa}$ pressure. The detailed making procedures of the $\mathrm{SiO}_{2} /$ epoxy composites haven been discussed in [1].

\subsection{Tribological tests}

A CSM tribometer of ball-on-disk configuration was used to test the composites under dry sliding conditions. $\varnothing 13 \mathrm{~mm} 100 \mathrm{Cr} 6$ bearing steel balls were mainly used as the counterparts balls (stationary), while $\mathrm{Al}_{2} \mathrm{O}_{3}$ balls were used to study the effects of humidity to avoid the influence of rusting. The density of the $100 \mathrm{Cr} 6$ steel and the $\mathrm{Al}_{2} \mathrm{O}_{3}$ balls are 7.8 and $3.9 \mathrm{~g} / \mathrm{cm}^{3}$, respectively, while their surface roughness $(\mathrm{Ra})$ values are about the same, $50 \mathrm{~nm}$. The standard sliding conditions were $60 \mathrm{~N}$ load, $2 \mathrm{~cm} / \mathrm{s}$ velocity, $35 \pm 2 \%$ relative humidity and at room temperature $\left(22 \pm 2{ }^{\circ} \mathrm{C}\right)$. To study the effect of various sliding conditions, in each test only one single parameter was varied. The normal load ranged from $0.5 \mathrm{~N}$ to $60 \mathrm{~N}$, whereas the relative humidity varied from $10 \%$ to $75 \%$. The sliding speed was varied from $0.5 \mathrm{~cm} / \mathrm{s}$ to $50 \mathrm{~cm} / \mathrm{s}$. The relative humidity was adjusted with feedback controlled flux of dry air or water vapor into the protection box. Water lubrication tests were performed with the sliding interface being immersed in distilled water. The temperature on the composite surface is measured with an infrared thermometer (Voltcraft IR 650-12D).

\subsection{Characterization of the worn surface}

After the tribo-tests, the morphology of the worn surfaces of the Epomet-PTFE composites and of the balls was inspected using light microscopy. Confocal microscopy (Nanofocus $\mu$ Surf) was used to measure the surface profile of the worn surfaces of the composites and the balls, for the assessment of the wear volume by a Matlab code with a margin of error of $\pm 5 \%$. To obtain the average elemental composition on the worn surfaces of the composites, at least three scans of energy dispersive X-ray spectroscopy (EDS, Philips XL-30 FEG ESEM) were executed with the size of the scanning areas about $465 \times 350 \mu \mathrm{m}^{2}$. 


\section{Results and discussion}

\subsection{Influence of lubricants}

The effect of PTFE contents in the composite on the mechanical properties is presented in Fig. 1(a). Both the hardness and compressive strength of the composites decreases as the content of PTFE increases, as PTFE has much weaker mechanical properties than $\mathrm{SiO}_{2}$ and epoxy. Plastic deformations of the composites were estimated via measuring the volume decrease of the composite wear track after only $5 \mathrm{~m}$ sliding distance and assuming all the corresponding volume change is attributed to the plastic deformation. It is seen that a higher plastic deformation is found in the composite with a higher PTFE content. Thus, although sufficient PTFE lubrication is desired, significantly weakened mechanical properties of the composites limits the content of PTFE.
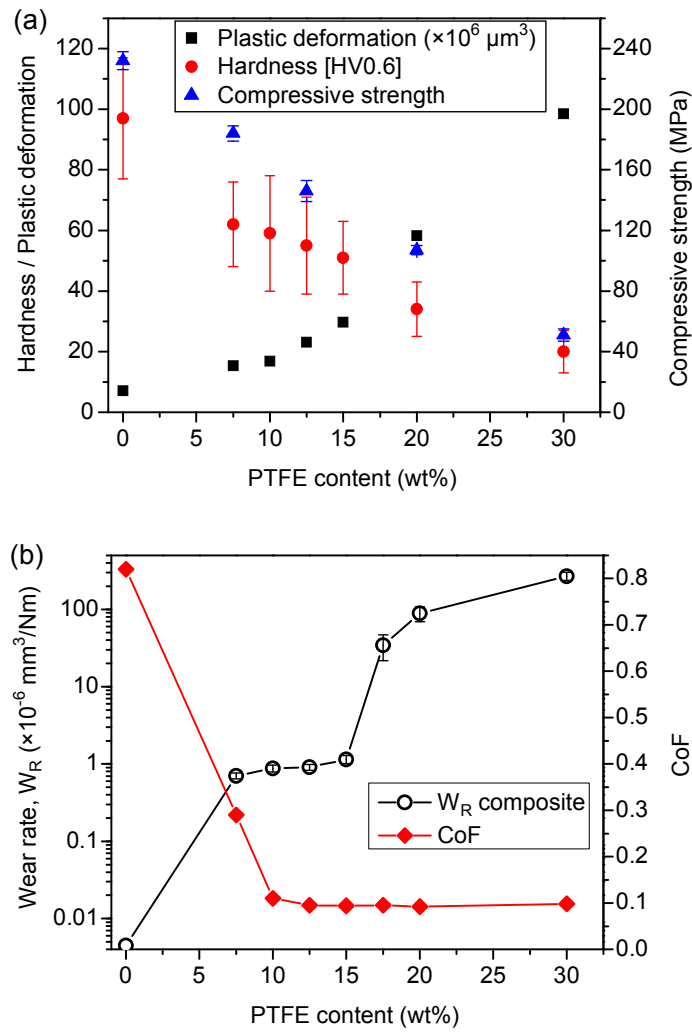

Figure 1: (a) Vickers hardness, plastic deformation and compressive strength of the composites with various PTFE contents. (b) Average CoF and wear rates of the composites sliding against the steel ball for $1000 \mathrm{~m}$ at $60 \mathrm{~N}$ normal load and $2 \mathrm{~cm} / \mathrm{s}$ sliding speed. 
The CoF results of the PTFE filled composites are shown in Fig. 1(b). Low CoF values $(<0.11)$ are measured within a sliding distance of $1000 \mathrm{~m}$ the PTFE content of the composite is not less than $10 \mathrm{wt} \%$. When decreasing the PTFE content below $10 \mathrm{wt} \%$, the average $\mathrm{CoF}$ considerably increases, indicating insufficient PTFE in the composite. Hence, $10 \mathrm{wt} \%$ PTFE is considered as the lower threshold, below which a low CoF value cannot be reached. Under $60 \mathrm{~N}$ load, there is also a higher threshold of the PTFE content above which the wear rate of the composites increases dramatically. The wear rate of the composites with PTFE content not less than $17.5 \mathrm{wt} \%$ is measured to be one or two orders of magnitude higher than that of the composites with not more than $15 \mathrm{wt} \%$ PTFE. The composites with 10 15 wt $\%$ PTFE content deliver the best triboperformance under a load of $60 \mathrm{~N}$ within the sliding distance of $1000 \mathrm{~m}$. A wear rate as low as about $8.4 \times 10^{-7} \mathrm{~mm}^{3} / \mathrm{Nm}$ is achieved for the composite with $12.5 \mathrm{wt} \%$ PTFE after sliding for $1000 \mathrm{~m}$. Having a high concentration ( $>50 \mathrm{wt} \%)$ of abrasive $\mathrm{SiO}_{2}$ particles in the composites, a low $\mathrm{CoF}$ and wear rate is still measured, implying the excellent lubricating property of PTFE under dry sliding.

To compare the lubrication property of graphite and PTFE, composites with $12.5 \mathrm{wt} \%$ solid lubricants but different combinations of PTFE and graphite content were synthesized. The friction results are shown in Fig. 2. It is seen that the $\mathrm{CoF}$ values increase with increasing graphite content (decreasing PTFE content). The wear rates of the $12.5 \mathrm{wt} \%$ PTFE sample, the $5 \mathrm{wt} \%$ PTFE $+7.5 \mathrm{wt} \%$ graphite sample and the $12.5 \mathrm{wt} \%$ graphite sample are measured to be $9 \times 10^{-7}, 93 \times 10^{-7}$, and $181 \times 10^{-7} \mathrm{~mm}^{3} / \mathrm{Nm}$, respectively. Both the friction and wear results suggest that the graphite shows a worse lubrication property than the PTFE under dry sliding conditions.

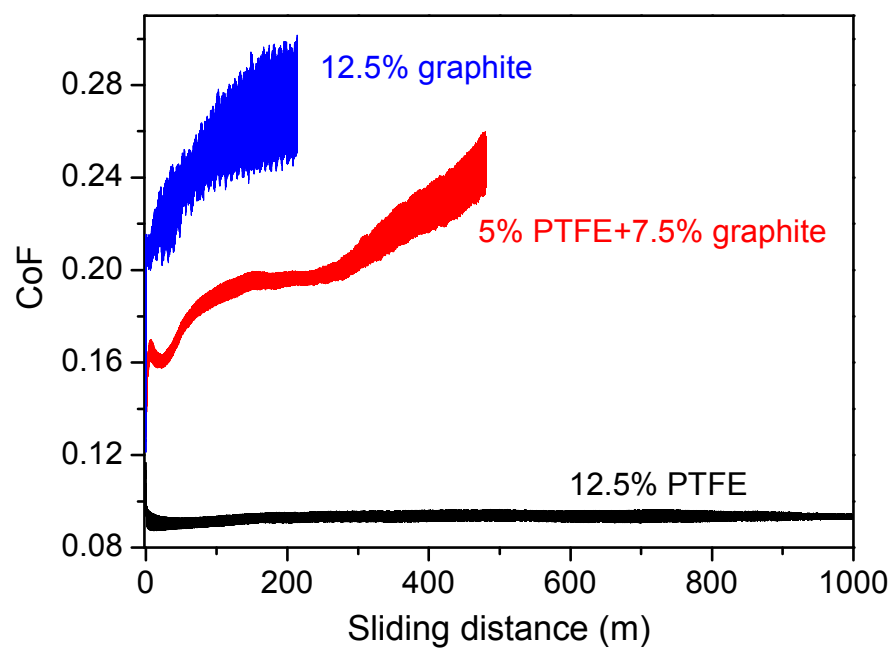

Figure 2: CoF curves of the composites with various PTFE and graphite contents, sliding against the $100 \mathrm{Cr} 6$ steel counterpart ball at $60 \mathrm{~N}$ normal load and $2 \mathrm{~cm} / \mathrm{s}$ speed. 


\subsection{Influence of normal load}

The loading condition of dry sliding bearings may vary over a large range in different applications, so a good understanding of the influence of normal load on the tribo-performance of PTFE based composites is also of importance.

The friction result of the composite with $12.5 \mathrm{wt} \%$ PTFE sliding against the steel ball under different loads is shown in Fig. 3. A general trend is an increase of $\mathrm{CoF}$ with a decreasing load. Moreover, there is a drastic increase of the $\mathrm{CoF}$ upon lowering the load from $10 \mathrm{~N}$ to $5 \mathrm{~N}$, in comparison with the less sharply changed $\mathrm{CoF}$ values measured under high loads $(10,30$ and $60 \mathrm{~N})$. It is clear that normal load plays an important role in the friction behavior of the PTFE-filled composite.

The different CoF could be attributed to different amount of PTFE in the sliding interface under various loads. To investigate the effect of load on the amount of PTFE on composite surfaces, EDS analyses were done after sliding for $20 \mathrm{~m}$ against the steel ball at $0.5 \mathrm{~N}, 5 \mathrm{~N}$ and $60 \mathrm{~N}$ load. The value of $F \mathrm{wt} \%$ on the worn composite surfaces increases with an increasing load, as shown in Fig. 3. This result suggests that sliding under a high load is beneficial in smearing PTFE over the $\mathrm{SiO}_{2}$ and epoxy surfaces in the wear track of the composites. This is attributed to a larger deformation of the composite under a higher load, which facilitates the squeezing out of the PTFE from the outer surface of the composite disc. A higher $\mathrm{CoF}$ at a lower load measured in this work is mainly attributed to a lower amount of PTFE on the composite surface.

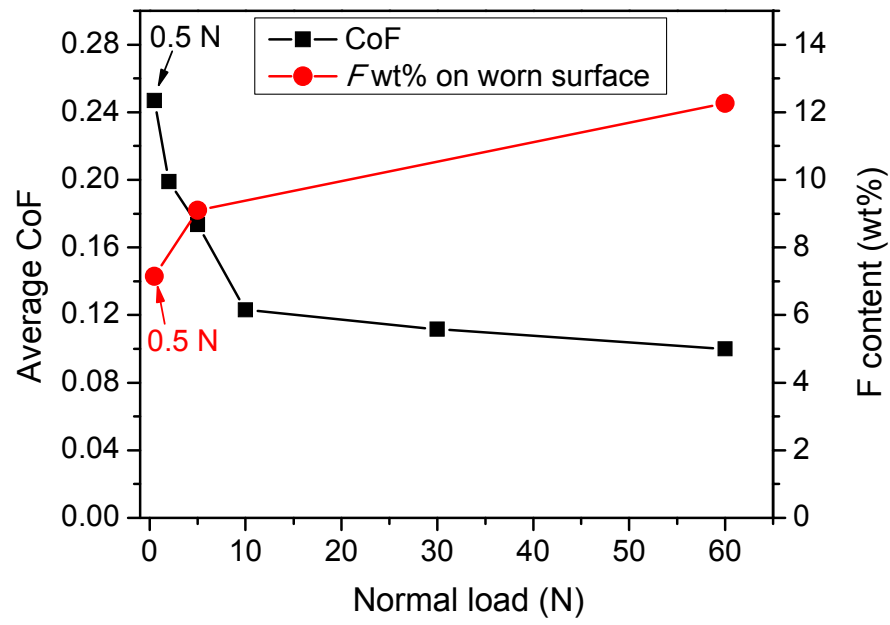

Figure 3: Average CoF values in $1000 \mathrm{~m}$, and EDS quantitative results of the $F$ weight percentage on the worn surface of the composite with $12.5 \mathrm{wt} \%$ PTFE after sliding for $20 \mathrm{~m}$ against the steel ball under different loads, at $2 \mathrm{~cm} / \mathrm{s}$ velocity and $35 \% \mathrm{RH}$. 


\subsection{Influence of sliding speed}

Sliding speed is another important factor to study because of the different speeds used in various applications. To study this, the composite with $12.5 \mathrm{wt} \%$ PTFE was tested against $100 \mathrm{Cr} 6$ steel balls with speed ranging from 0.5 to $50 \mathrm{~cm} / \mathrm{s}$.

It is measured that the wear rate of the composites is not evidently influenced by the sliding speed and is around $9 \times 10^{-7} \mathrm{~mm}^{3} / \mathrm{Nm}$ in all the cases. The CoF curves are shown in Fig. 4(a). It is clear that the CoF increases with an increase of sliding speed from 0.5 to $50 \mathrm{~cm} / \mathrm{s}$.
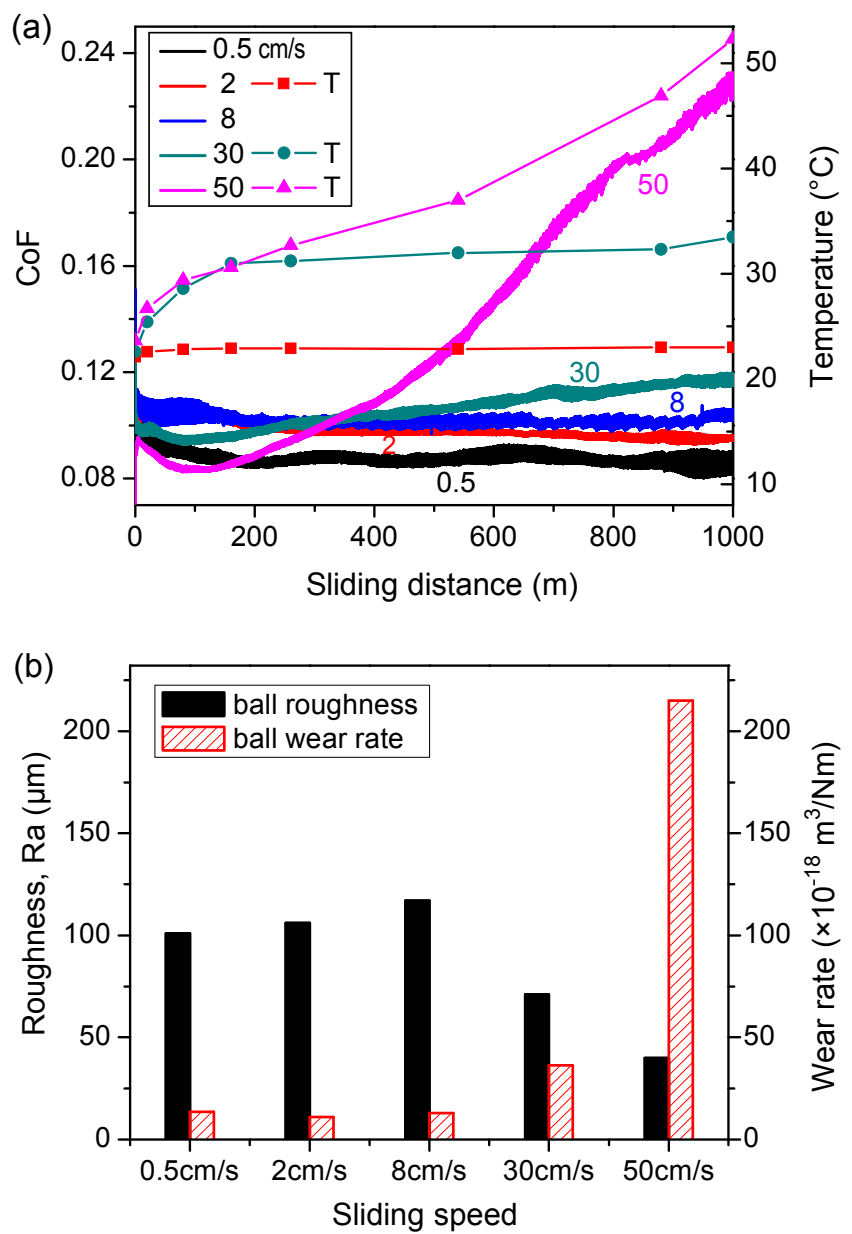

Figure 4: (a) CoF curves and the temperatures at the center of the surface of the composite with $12.5 \mathrm{wt} \%$ PTFE when sliding the $100 \mathrm{Cr} 6$ steel ball, and (b) surface roughness and wear rates of the worn steel balls, at various sliding speeds, $60 \mathrm{~N}$ load and 35\% RH. 
Temperature were measured in the center of the composite top surface after different sliding distances and shown in Fig. 4(a). An increase of the surface temperature is also found with the increasing sliding speed, which is ascribed to frictional heating at high sliding speeds. It is seen that the increase of surface temperature coincides fairly well with the increase of the CoF, especially at high sliding speeds.

Mclaren and Tabor also found the raise of $\mathrm{CoF}$ in this speed range, which was attributed to the temperature sensitivity of the friction behavior to the viscoelastic origin of thermoplastic crystalline PTFE [13]. At high speeds (30 and $50 \mathrm{~cm} / \mathrm{s}$ ), much less transfer film on steel surface than at low speeds is found with light microscopy (not shown here), which is also responsible for the increase of CoF. A higher wear rate of the steel ball is measured with a higher sliding speed, as shown in Fig. 4(b), which suggests a larger amount of back-transferred steel on the worn composite surface. It was found that considerable amount of back-transferred steel on the worn composite surface could lead to a significant increase of friction [1]. Thus, this could also contribute to a higher friction. It seems that many reasons could be responsible for the increase of $\mathrm{CoF}$ with increasing sliding speed, but roughening of the steel counterpart surface is not one of them. It is found in Fig. 4(b) that the surface roughness of the worn steel surface first increases with increasing speed but decreases with further increasing sliding speed from 8 to $50 \mathrm{~cm} / \mathrm{s}$. This indicates that the increase of $\mathrm{CoF}$ with increasing sliding speed is not due to the increase of roughness of the steel surface.

\subsection{Influence of humidity and water}

For outdoor applications, the self-lubricating composites should be able to withstand high humidity and even sliding in rainwater. Thus, the composites with $12.5 \mathrm{wt} \%$ PTFE or graphite were tested via sliding against the $\mathrm{Al}_{2} \mathrm{O}_{3}$ ball at different relative humidity as well as with distilled water lubrication. Note that $\mathrm{Al}_{2} \mathrm{O}_{3}$ balls were used to study the effects of humidity to avoid the influence of rusting of the steel balls.

The CoF results are shown in Fig. 5. It is clearly seen that the CoF of the composites with $12.5 \mathrm{wt} \%$ PTFE decreases with increasing relative humidity. The CoF decreases by about $7.6 \%$ when increasing the relative humidity from $10 \%$ to $75 \%$. As to the composites with $12.5 \mathrm{wt} \%$ graphite, a similar trend of $\mathrm{CoF}$ change was observed with varying relative humidity. The decrease of CoF with increasing relative humidity in both cases is attributed to the lubrication of absorbed water molecules in the sliding interfaces. The change of $\mathrm{CoF}$ is more sensitive at low relative humidity than at high relative humidity in the case of graphite filled composite. $\mathrm{CoF}$ decreases $12.5 \%$ when increasing the relative humidity from $10 \%$ to $75 \%$, while $11 \%$ decrease was measured from $10 \%$ to $35 \%$ relative humidity.

Under water lubrication, however, the CoF of the composites with $12.5 \mathrm{wt} \%$ PTFE decreases in the first $240 \mathrm{~m}$ sliding (reaching 0.068), followed by a significant increase of $\mathrm{CoF}$ to 0.165 after $500 \mathrm{~m}$ sliding, as shown in Fig. 6. This indicates that both PTFE and water lubrication play important roles in the sliding 
interface. However, the significant increase of $\mathrm{CoF}$ after $300 \mathrm{~m}$ sliding against the composite with $12.5 \mathrm{wt} \%$ PTFE could suggest a detrimental role of water on the PTFE lubrication. The deleterious effect of water on the wear performance of PTFE filled polymer composites is attributed mainly to the inhibition of transfer film formation [14-16]. Regarding the composites with $12.5 \mathrm{wt} \%$ graphite, the $\mathrm{CoF}$ shows a much lower value under water lubrication than that under dry sliding. This indicates the positive role of water lubrication on the friction behavior of the graphite filled composite, probably due to the comparable lubricating property of water and graphite in this case.

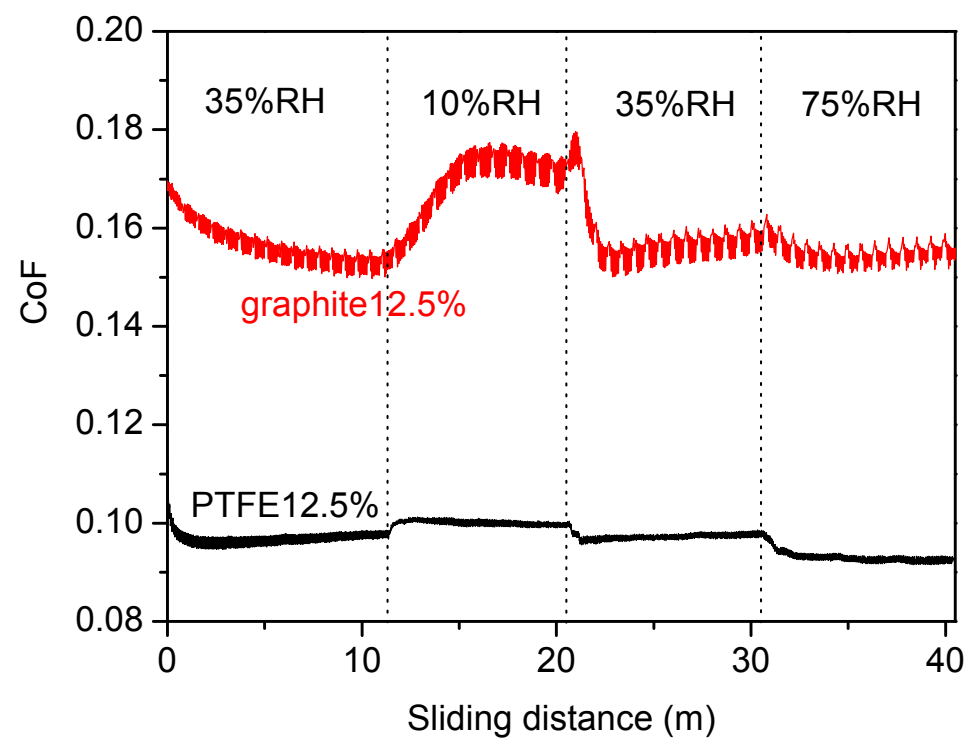

Figure 5: CoF curves of the composites with $12.5 \mathrm{wt} \%$ PTFE and graphite in a tribo-test at $30 \mathrm{~N}$ under changing relative humidity $(\mathrm{RH})$, sliding against the $\mathrm{Al}_{2} \mathrm{O}_{3}$ ball, at $2 \mathrm{~cm} / \mathrm{s}$ velocity. Note: Each time, there is a ramping period after starting to change relative humidity, which is reflected in the large slopes of $\mathrm{CoF}$ curves.

It should be noted that the wear rates of the PTFE and graphite filled composites are both reduced under water lubrication, while the wear rates of the $\mathrm{Al}_{2} \mathrm{O}_{3}$ ball in both cases are increased. For instance, the wear rate of the graphite filled composite under water lubrication is around $9 \times 10^{-6} \mathrm{~mm}^{3} / \mathrm{Nm}$, about 9 times lower than that under dry sliding at $30 \mathrm{~N}$ load. The wear rate of the $\mathrm{Al}_{2} \mathrm{O}_{3}$ ball reaches about $6 \times 10^{-7} \mathrm{~mm}^{3} / \mathrm{Nm}$ under water lubrication when sliding against the $12.5 \mathrm{wt} \%$ PTFE filled composites, increasing by more than one order of magnitude than under dry sliding. This suggests the positive role of water lubrication on the wear behavior of the PTFE and graphite filled composites, whereas it has a negative influence on the wear behavior of the $\mathrm{Al}_{2} \mathrm{O}_{3}$ ball due to the lack of protection of the transfer films. 


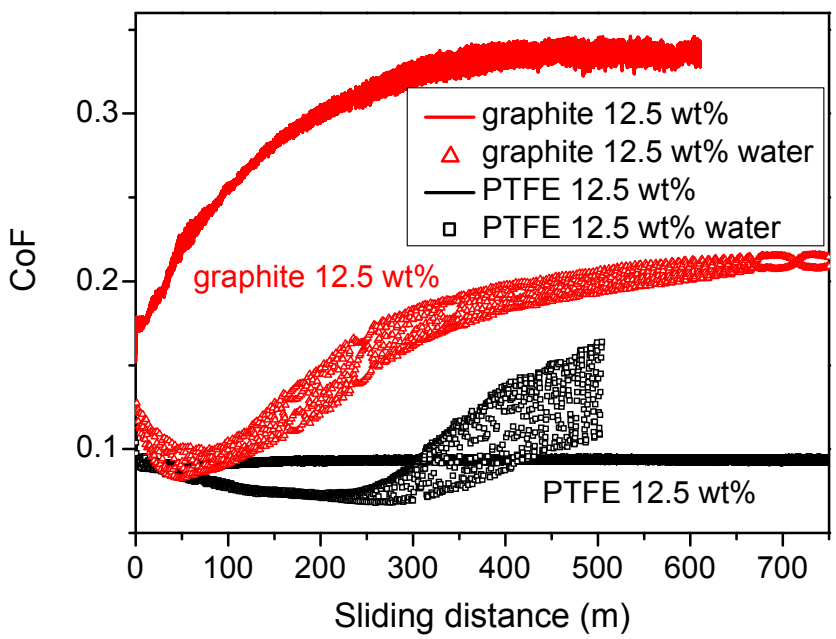

Figure 6: CoF curves of the composites with $12.5 \mathrm{wt} \%$ PTFE (60 N load) or $12.5 \mathrm{wt} \%$ graphite $(30 \mathrm{~N}$ load) under dry sliding and distilled water lubrication (dotted curves), sliding against the $\mathrm{Al}_{2} \mathrm{O}_{3}$ ball, at $2 \mathrm{~cm} / \mathrm{s}$ velocity.

\section{Conclusions}

Via varying PTFE concentrations, it is found that the addition of PTFE weakens the mechanical properties of the composites. The composites with 10 15 wt.\% PTFE content deliver the best tribo-performance under a load of $60 \mathrm{~N}$. With the same amount in the composite, graphite yields a worse lubrication property than PTFE under dry sliding condition.

Friction results indicate that a higher load leads to a lower CoF of the PTFEfilled composite, which is mainly attributed to more PTFE being squeezed out from the outer surface of the composite disc under a higher load. A higher sliding speed yields a higher CoF. This is more significant at high speeds $(>30 \mathrm{~cm} / \mathrm{s})$, in which considerable increases of temperature on the composite surface accompanies the increase of $\mathrm{CoF}$. Several reasons could be responsible for the increase of $\mathrm{CoF}$ with increasing sliding speed, such as viscoelastic origin of thermoplastic crystalline PTFE, less PTFE transfer films formed at higher speeds and more back-transferred steel onto composite surfaces at higher speeds.

The CoF decreases as relative humidity increases for both PTFE and graphite filled epoxy composites, which is attributed to the lubrication of absorbed water vapor. When sliding under water lubrication, a significant increase of $\mathrm{CoF}$ of the PTFE filled composite was found after sliding for more than $300 \mathrm{~m}$. The deleterious effect of water is attributed mainly to the inhibition of PTFE transfer film formation. Water lubrication leads to a better wear performance of the PTFE and graphite filled composites, whereas it gives rise to a worse wear performance of the $\mathrm{Al}_{2} \mathrm{O}_{3}$ ball due to the lack of protection of the transfer films. 


\section{References}

[1] Shen, J.T., Top, M., Pei, Y.T., \& De Hosson, J.Th.M., Wear and friction performance of PTFE filled epoxy composites with a high concentration of $\mathrm{SiO}_{2}$ particles. Wear, 322-323, pp. 171-180, 2015.

[2] Biswas, S.K., \& Vijayan, K., Friction and wear of PTFE-a review. Wear 158(1-2), pp. 193-211, 1992.

[3] Bijwe, J., Neje, S., Indumathi, J., \& Fahim, M., Friction and wear performance evaluation of carbon fibre reinforced PTFE composite. $J$ Reinf Plast Compos, 21(13), pp. 1221-1240, 2002.

[4] Benabdallah, H., Friction and wear of blended polyoxymethylene sliding against coated steel plates. Wear, 254(12), pp. 1239-1246, 2003.

[5] Unal, H., Mimaroglu, A., Kadioglu, U., \& Ekiz, H., Sliding friction and wear behaviour of polytetrafluoroethylene and its composites under dry conditions. Mater Des, 25(3), pp. 239-245, 2004.

[6] Kragelskii, IV., Friction and wear. Elmsford: Pergamon Press; 1982.

[7] Tanaka, K., \& Miyata, T., Studies on the friction and transfer of semicrystalline polymers. Wear, 41(2), pp. 383-398, 1977.

[8] Krick, B.A., Ewin, J.J., Blackman, G.S., Junk, C.P., \& Gregory Sawyer, W., Environmental dependence of ultra-low wear behavior of polytetrafluoroethylene (PTFE) and alumina composites suggests tribochemical mechanisms. Tribol Int 51, pp. 42-46, 2012.

[9] Mens, J.W.M., De Gee, A.W., Friction and wear behaviour of 18 polymers in contact with steel in environments of air and water. Wear, 149(1-2), pp. 255-268, 1991.

[10] Jia, J.H., Chen, J.M., Zhou, H.D., Hu, L.T., \& Chen, L., Comparative investigation on the wear and transfer behaviors of carbon fiber reinforced polymer composites under dry sliding and water lubrication. Compos Sci Technol, 65(7-8), pp. 1139-1147, 2005.

[11] Savage, R.H., Graphite lubrication. Journal of Applied Physics, 19(1), pp. 1-10, (1948).

[12] Bowden, F. P., \& Young, J. E., Friction of diamond, graphite, and carbon and the influence of surface films, Proceedings of the Royal Society of London. Series A, Mathematical and Physical Sciences, 208(1095), pp. 444-455, 1951.

[13] McLaren, K.G., \& Tabor, D., Nature, 197, pp. 856-858, 1963.

[14] Lancaster, J.K., Accelerated wear testing of PTFE composite bearing materials. Tribol Int, 12(2), pp. 65-75, 1979.

[15] Meng, H., Sui, G.X., Xie, G.Y., \& Yang, R., Friction and wear behavior of carbon nanotubes reinforced polyamide 6 composites under dry sliding and water lubricated condition. Compos Sci Technol, 69(5), pp. 606-611, 2009.

[16] Friedrich, K. (ed.), Friction and Wear of Polymer Composites, Composite Materials Series (Vol. 1), Amsterdam: Elsevier; 1986. 